\title{
Osteoporosis case finding in the general practice: phalangeal radiographic absorptiometry with and without risk factors for osteoporosis to select postmenopausal women eligible for lumbar spine and hip densitometry
}

\author{
Katharina M. Gasser · Christian Mueller \\ Marcel Zwahlen · Manfred Kaufmann · Gaby Fuchs \\ Romain Perrelet · Gilbert Abetel · Ulrich Bürgi \\ Kurt Lippuner
}

Received: 25 June 2004/ Accepted: 23 December 2004/Published online: 12 February 2005

(C) International Osteoporosis Foundation and National Osteoporosis Foundation 2005

\begin{abstract}
Mass screening for osteoporosis using DXA measurements at the spine and hip is presently not recommended by health authorities. Instead, risk factor questionnaires and peripheral bone measurements may facilitate the selection of women eligible for axial bone densitometry. The aim of this study was to validate a case finding strategy for postmenopausal women who would benefit most from subsequent DXA measurement by using phalangeal radiographic absorptiometry (RA) alone or in combination with risk factors in a general practice setting. The sensitivity and specificity of this strategy in detecting osteoporosis (T-score $\leq 2.5 \mathrm{SD}$ at the spine and/or the hip) were compared with those of the current reimbursement criteria for DXA measurements in Switzerland. Four hundred and twenty-three postmenopausal women with one or more risk factors for osteoporosis were recruited by 90 primary care physicians who also performed the phalangeal RA measurements. All women underwent subsequent DXA
\end{abstract}

K.M. Gasser · C. Mueller · M. Kaufmann · G. Fuchs R. Perrelet $\cdot$ K. Lippuner $(\square)$

Osteoporosis Policlinic, University Hospital of Berne, 3010 Berne, Switzerland

E-mail: kurt.lippuner@insel.ch

Tel. + 41-31-6323128

Fax: +41-31-6329596

M. Zwahlen

Department of Social and Preventive Medicine, University of Berne, Berne, Switzerland

G. Abetel

Swiss College of Family Practitioners,

Clinical Research Group of the Swiss Foundation

for General Medicine, Berne, Switzerland

U. Bürgi

Department of Internal Medicine,

University Hospital of Berne, Berne, Switzerland measurement of the spine and the hip at the Osteoporosis Policlinic of the University Hospital of Berne. They were allocated to one of two groups depending on whether they matched with the Swiss reimbursement conditions for DXA measurement or not. Logistic regression models were used to predict the likelihood of osteoporosis versus "no osteoporosis" and to derive ROC curves for the various strategies. Differences in the areas under the ROC curves (AUC) were tested for significance. In women lacking reimbursement criteria, RA achieved a significantly larger AUC $(0.81 ; 95 \%$ CI $0.72-0.89)$ than the risk factors associated with patients' age, height and weight $(0.71 ; 95 \%$ C.I. $0.62-0.80)$. Furthermore, in this study, RA provided a better sensitivity and specificity in identifying women with underlying osteoporosis than the currently accepted criteria for reimbursement of DXA measurement. In the Swiss environment, RA is a valid case finding tool for patients with risk factors for osteoporosis, especially for those who do not qualify for DXA reimbursement.

Keywords Case finding - DXA - General practice · Postmenopausal osteoporosis - Radiographic absorptiometry $\cdot$ Risk factors

\section{Introduction}

Bone mineral density (BMD) measurement at the hip and lumbar spine using dual-energy X-ray absorptiometry (DXA) is widely accepted as the gold standard in the diagnosis of osteoporosis and as a basis for decision making and monitoring of osteoporosis treatment $[1,2$, 3]. However, the current guidelines do not recommend BMD measurement with axial DXA as a mass screening tool [3]. In Switzerland as in other European countries, 
DXA is covered by basic health insurance in a restricted number of clinical situations (Table 1).

Although hip fracture prediction with BMD measurement alone is at least as good as blood pressure readings to predict stroke [4], there are no validated mass screening strategies based on BMD measurement with axial DXA available to date. On the other hand, modern treatment options of osteoporosis targeted at reducing fracture risk have been adequately documented only in patients with low BMD at the spine and/or hip. Therefore, various case finding strategies using individual risk factors or risk questionnaires have been proposed to select women for bone densitometry $[5,6,7,8$, $9,10,11,12,13,14,15]$. Treatment would be considered in individuals subsequently shown to have low BMD at the spine and/or hip and who thereby have a high fracture risk [16, 17].

Another approach to facilitate the selection of women eligible for bone densitometry was the development and validation of osteoporosis screening devices, based on bone measurements at peripheral sites of the skeleton. Among these techniques, phalangeal ultrasound [18], computed digital absorptiometry [19, 20] and radiographic absorptiometry (RA) $[21,22,23,24$, $25,26,27,28]$ have documented reasonable sensitivity and specificity, which were, however, not sufficiently good to replace DXA for the diagnosis of osteoporosis. Recently, we addressed the question of whether and how well radiographic absorptiometry of the phalanges predicted osteoporosis at the spine or hip (as diagnosed by DXA) and whether a two-step diagnostic strategy (using RA as the first line to identify patients with low bone mass and DXA as the second line to assess the diagnosis of osteoporosis and take the treatment decision) was cost-effective in postmenopausal women [25]. However, although the latter was the case, that study did not assess the value of risk factors taken alone or in combination with RA to increase the specificity and sensitivity in detecting women with osteoporosis at the spine and/or the hip as defined by the WHO (T-score $\leq 2.5 \mathrm{SD})[3]$.

The aim of this study was to validate a case finding strategy for postmenopausal women who would benefit most from subsequent DXA measurement to diagnose osteoporosis. Therefore, the specificity and sensitivity of RA measurements, alone or in combination with selected risk factors, in predicting low bone mass were

Table 1 Reimbursed DXA indications in Switzerland

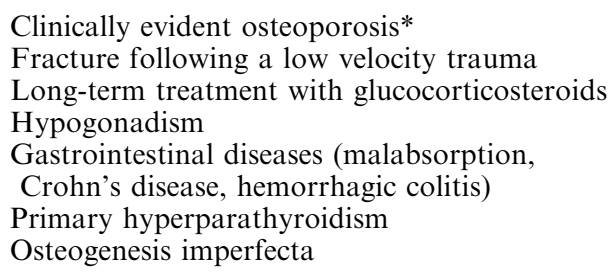

*E.g., clinically documented height loss estimated in a general practice setting in Switzerland. Furthermore, the efficiency of this case-finding strategy was compared to today's medical practice based on the current Swiss reimbursement criteria for DXA measurements.

\section{Materials and methods}

\section{Participants}

Four hundred and twenty-three postmenopausal women were recruited by 90 participating primary care physicians in the cantons of Berne and Vaud in Switzerland, listed in the Appendix. Women were eligible for the study if they were postmenopausal, older than 45 years of age and presented one or more risk factors for osteoporosis [history of hypogonadism, gastrointestinal disease (malabsorption, Crohn's disease or hemorrhagic colitis), anamnestic or current long-term treatment with glucocorticosteroids ( $>3$ months, $>7.5 \mathrm{mg}$ equivalent of prednisone per day), history of hysterectomy or ovariectomy, low dietary calcium intake, positive family history of osteoporosis, past or current nicotine abuse ( $>10$ cigarettes a day), substitution with thyroid hormones and/or potential manifestations of osteoporosis (history of fracture following a low velocity trauma or of height loss $\geq 3.5 \mathrm{~cm})$ ].

\section{Methods}

The individual risk of a patient was assessed by the local primary care physician using a standardized questionnaire with the above-mentioned risk factors. If one or more risk factors were present, age, height and weight were recorded, and a phalangeal X-ray of the nondominant hand (two exposures on the same film) was performed at the physician's office. This X-ray was sent by mail to the Osteoporosis Policlinic of the University Hospital of Berne for digital computerization. Subsequently, all participating women were invited by the Osteoporosis Policlinic, in agreement with the participating physician, to undergo DXA measurement.

\section{Dual-energy X-ray absorptiometry (DXA)}

Bone densitometry was performed at the lumbar spine (LS, second to fourth lumbar vertebra) and at the femoral neck (FN) using a Hologic QDR 1000 densitometer (Hologic Inc., Bedford, Mass.). Bone mineral density (BMD) was expressed as $\mathrm{g} / \mathrm{cm}^{2}$ of hydroxyapatite and Tscores (SD from peak bone mass). T-scores were based on a quadratic regression calculated from a reference population of 318 normal Caucasian women (2080 years, body mass index $18-31 \mathrm{~kg} / \mathrm{m}^{2}$ ) living in the area of Berne. Peak bone mass (mean value \pm SD) was $1.044 \pm 0.117$ at the lumbar spine (L2-L4) and 
$0.827 \pm 0.098$ at the femoral neck. Subjects with a Tscore at the lumbar spine and/or femoral neck below or equal to $-2.5 \mathrm{SD}\left(0.752 \mathrm{~g} / \mathrm{cm}^{2}\right.$ and $0.582 \mathrm{~g} / \mathrm{cm}^{2}$, respectively) were defined as osteoporotic, in accordance with the WHO definition [3]. Daily quality control was performed using the anthropometric spine phantom supplied by the manufacturer: overall precision error was $0.3 \%$ in vitro, and in vivo mean precision error was $1.0 \%$ in our hands.

\section{Radiographic absorptiometry of the phalanges (RA)}

The technique has been described in detail earlier [21, 26, 28]. Briefly, fingers of the non-dominant hand and an aluminum wedge were radiographed with the available radiographic equipment at the site, using a non-screened pre-packed sealed industrial film by Kodak. Two exposures $(50 \mathrm{kV}, 300 \mathrm{mAs}$ and $60 \mathrm{kV}, 150 \mathrm{mAs}$; focus distance $1 \mathrm{~m}$ ) were performed on the same film, which was developed at the primary care physician's office and then sent by regular mail to the Osteoporosis Policlinic of the University Hospital of Berne, where it was digitized for subsequent computer analysis using a high resolution video camera (OsteoGram Processing System, CompuMed Inc, Calif.). The regions of interest were defined such as to encompass the wedge as well as the middle phalanges of the index, third and fourth fingers. Interference by soft tissues was cancelled out mathematically by subtracting soft tissue absorption on either side of the bone for each scan line. The volumic density of composite bone was calculated in arbitrary units (AU) for each phalange and the results averaged. The results were considered as not valid if the difference between the two exposures exceeded $2 \%$. The skin dose on the hand was estimated to amount to $0.1 \mathrm{mSv}$ [29] and the effective dose to $1 \mu \mathrm{Sv}$, i.e., similar to the radiation dose from DXA [30]. The precision error was in our hands is 1$1.5 \%$.

\section{Statistical analysis}

Participants were separated into two groups for the analysis: group 1 consisted of women who met one or more of the current reimbursement criteria for DXA in Switzerland shown in Table 1 and group 2 consisted of all other women. In each group, three diagnostic categories were created, based on the T-scores at the lumbar spine and femoral neck measured by DXA: "normal" (T-score >-1 SD at LS and FN), "osteopenia" (T-score $\leq 1 \mathrm{SD}$ at $\mathrm{LS}$ and/or FN but $>-2.5 \mathrm{SD}$ at either site) and "osteoporosis" (T-score $\leq 2.5 \mathrm{SD}$ at LS and/or FN). In both groups significance tests were done to assess differences in patient characteristics and frequency of risk factors between the three categories. Chisquare test statistics for categorical variables and ANOVA $F$-values for continuous variables were calculated. RA-test characteristics were analyzed after pooling of the categories "normal" and "osteopenia" into a "no osteoporosis" category.

Logistic regression models were used to predict the likelihood of osteoporosis (versus "no osteoporosis") and to derive receiver operating characteristics (ROC) curves that summarized test specificity and sensitivity at different cut-off values. Five different logistic regression models were defined, including the following variables: age, height and weight (model 1), age, height and weight combined with all risk factors (model 2), RA measurement alone (model 3), RA measurement combined with age, height and weight (model 4) and RA measurement combined with age, height and weight and all risk factors (model 5). In these regressions age was centered at 65 years, weight at $67 \mathrm{~kg}$, height at $160 \mathrm{~cm}$ and RA measurement at $91 \mathrm{AU}$. Differences in the areas under the ROC curves were tested for significance. In addition, the sensitivity and specificity of RA were calculated for selected RA cut-off values $(<100,<95,<90,<87.5$, $<85 \mathrm{AU}$ ) in the group of women without a reimbursed DXA indication (group 2), using "osteoporosis" as the disease definition. All statistical analyses were done with Stata Statistical Software, version 8.2.

This study was a protocol extension of an earlier pilot study approved by the Ethical Review Committee of the University Hospital of Berne, and written informed consent was obtained from all participants.

\section{Results}

X-rays of the phalanges and risk questionnaires were obtained from 423 participants recruited by 90 general practitioners. Forty-one participants were excluded from the analysis: 23 had X-rays that could not be evaluated due to either technical artifacts or to major deformities of the interphalangeal joints. An additional nine participants had non-reliable DXA results [physical inability to lie in a supine position $(n=1)$, bilateral total hip endoprosthesis $(n=3)$, metal implants in the lumbar spine $(n=2)$ and a discrepancy between T-scores of the lumbar spine and femoral neck of more than $3 \mathrm{SD}$ $(n=3)$ ]; eight participants were younger than 45 years and from one participant, clinical data were not available. The data sets from 382 participants aged 45 to 91 years (mean $66.9 \pm 10.1$ years) with complete information on risk factors, RA value and DXA measurement at LS and FN were analyzed (Fig. 1).

\section{Participants' characteristics}

Group 1 consisted of 190 women who met at least one eligibility criteria for DXA reimbursement. Nineteen percent of the patients in this group had normal BMD values, $42 \%$ had osteopenia and $39 \%$ had osteoporosis either at the lumbar spine and/or the femoral neck. These three categories differed for age $(P=0.0002)$, weight, BMI and RA values $(P<0.0001$ for all three), 
Fig. 1 Study design

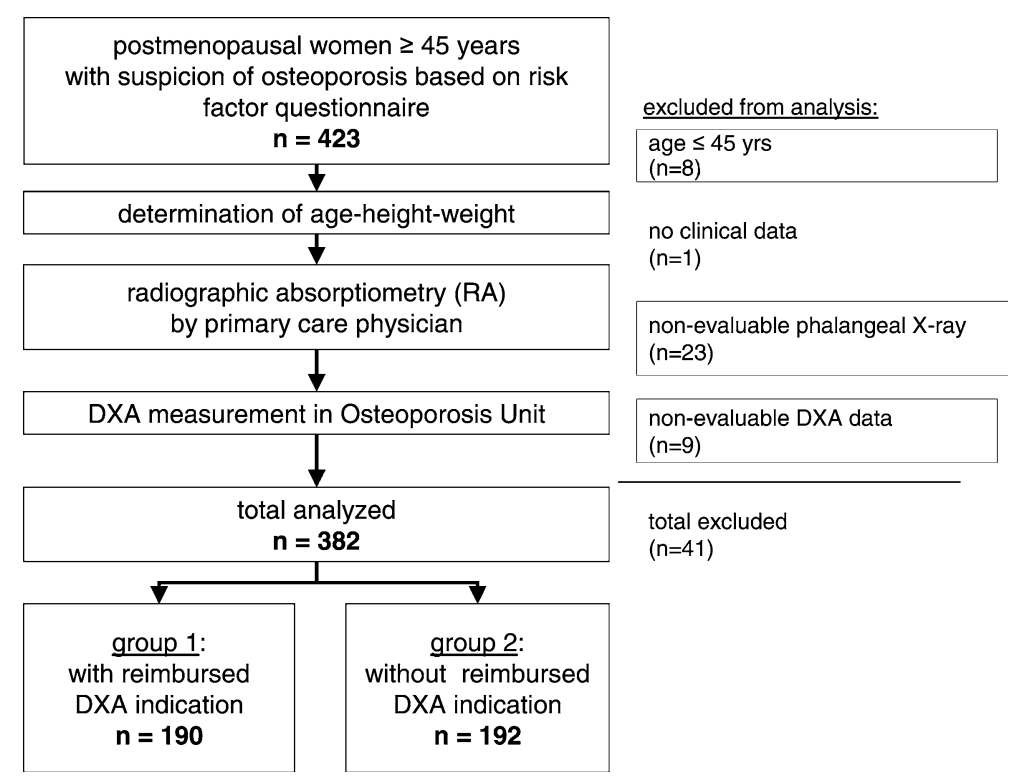

but not for height ( $P=0.119$ ), patients with osteoporosis being significantly older, with a lower body weight, BMI and RA value than normal and osteopenic participants (Table 2).

Group 2 consisted of 192 women who had no eligibility criteria for DXA reimbursement. Twenty-six percent of the patients in this group had normal BMD values, $56 \%$ had osteopenia and $18 \%$ had osteoporosis. These three categories differed for age $(P=0.0065)$, height $(P=0.023)$, weight $(P=0.001)$, BMI $(P=0.039)$ and RA values $(P<0.0001)$, patients without osteoporosis being significantly younger, taller, heavier and having higher RA values than those with osteoporosis.

\section{Areas under the ROC curves (AUC)}

In both groups, the combination of the parameters age, height and weight resulted in an AUC of 0.7 (95\% C.I. $0.62-0.79$ ). The inclusion of additional risk factors did not significantly improve the AUC, in either group. However, RA, either alone (group 2) or together with age, height and weight (group 1) allowed for a significant improvement of the AUC, which was increased beyond 0.8 . The inclusion of additional risk factors did not allow for a significantly larger AUC in patients without a reimbursed DXA indication (Fig. 2, Table 3).

\section{Sensitivity and specificity of the RA measurement}

In participants without a reimbursed DXA indication, the RA cut-off value of 95 arbitrary units (AU) or below provided a sensitivity of $91.4 \%$ and a specificity of $45.9 \%$ to detect osteoporosis at the spine or the hip (Table 4). In other words, more than $90 \%$ of the patients with underlying osteoporosis would be identi- fied if the RA cut-off value were set at 95 AU. In contrast, the presence of a reimbursed DXA indication in this patient population with prevalent risk factors for osteoporosis had a sensitivity of $67.9 \%$ and a specificity of $57.5 \%$ to predict osteoporosis (Table 5). In other words, based on current DXA reimbursement criteria, less than $70 \%$ of the patients with underlying osteoporosis are correctly identified, while almost $60 \%$ of those not having osteoporosis are identified as such.

Cut-off values for RA measurement were established for the entire study population (groups 1 and 2), which resulted in a better sensitivity and specificity than the current clinical criteria for DXA reimbursement in Switzerland (Tables 4, 5).

\section{Discussion}

The aim of our study was to validate a new case-finding strategy for osteoporosis applicable to practicing physicians in their daily routine and to compare it with today's DXA reimbursement-driven practice in Switzerland. According to the latter, screening for osteoporosis using DXA is reimbursed by health insurances only in a restricted number of circumstances, such as clinically evident osteoporosis or overt fracture after a low velocity trauma Table (1). Furthermore, according to the Federal Health Office, osteoporosis treatment is to be reimbursed by health insurances only for persons who fulfill the WHO definition criteria for osteoporosis (T-score $\leq-2.5 \mathrm{SD}$ ) at the lumbar spine and/or hip using DXA.

In the present study, three questions were addressed: (1) What are the sensitivity and specificity of the current DXA reimbursement criteria-as proposed by Swiss health authorities - in detecting osteoporosis at the spine and/or hip in postmenopausal women? (2) What would the sensitivity/specificity profile of phalangeal RA be in 


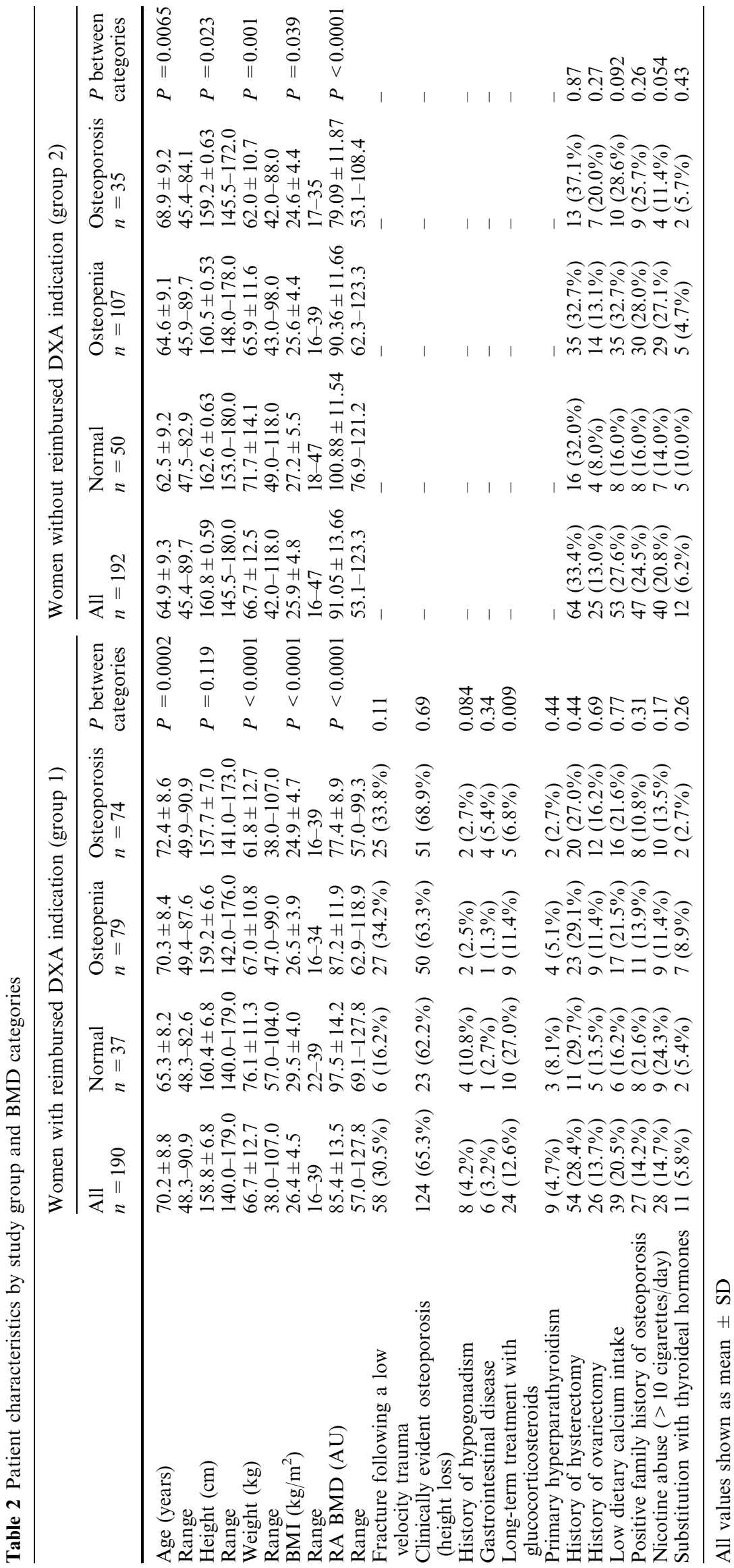



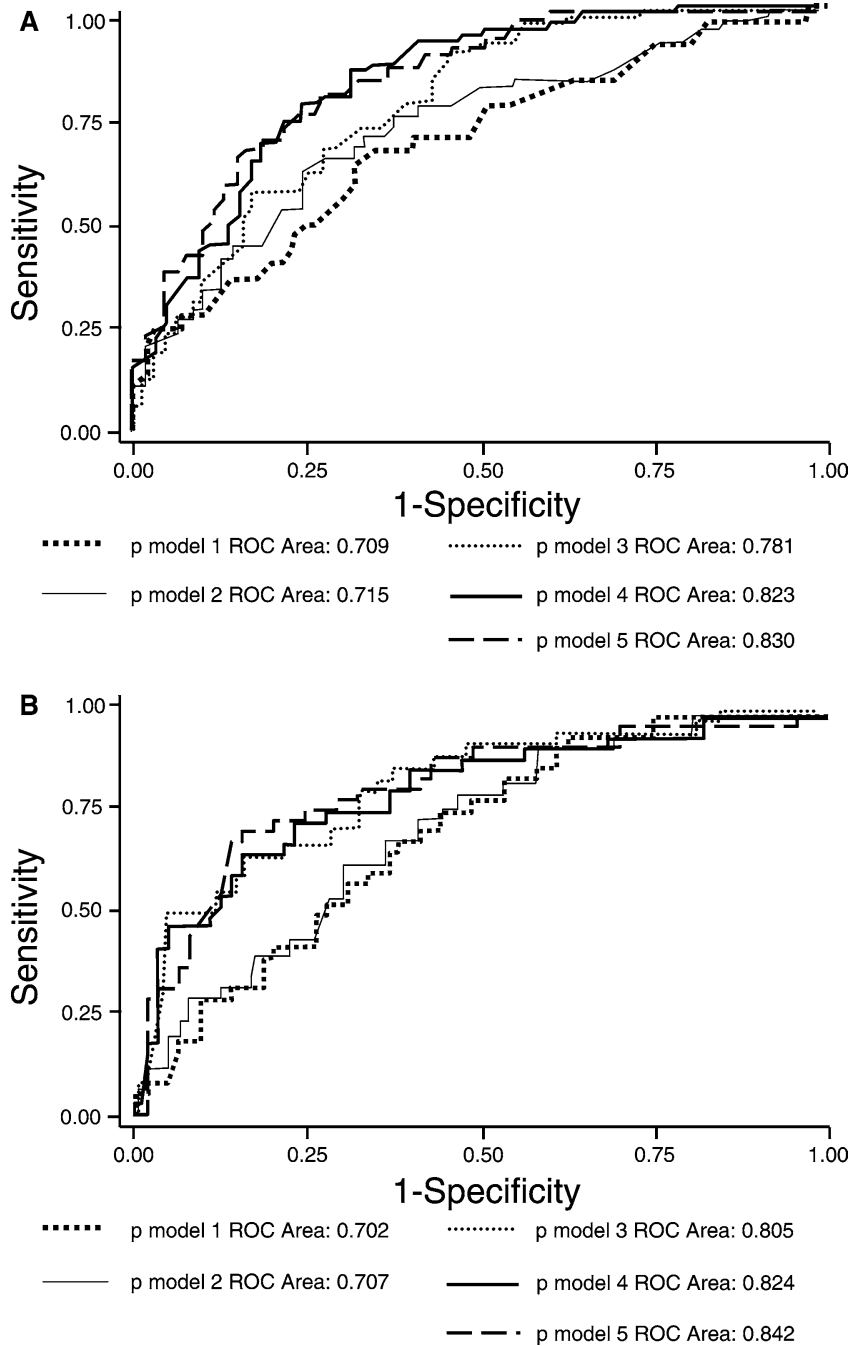

Fig. 2 Receiver operating characteristic (ROC) testing the sensitivity and the specificity of risk factors and RA, alone and combined. A Group 1 (women with reimbursed DXA indication), B Group 2 (women without reimbursed DXA indication) this very same population? (3) Would phalangeal RA allow for preselection of postmenopausal women with low bone mass who do not fulfill current DXA reimbursement criteria (although exhibiting well-established risk factors), and if so, what would the specificity and sensitivity of this approach be, as compared with the sole use of general risk factors for osteoporosis?

As documented by the significantly larger AUC achieved by adding RA to the risk factors and age and anthropometric parameters (height, weight), RA allowed for the preselection of postmenopausal women with low bone mass. There are numerous studies showing that risk factors are useful in predicting osteoporosis when applied to the general population of women aged 45 years and older $[8,14,15]$. In those studies, specificity ranged between 40 and $60 \%$ at a sensitivity level of $90 \%$, but has been reported to be as low as $20 \%$ in older women [8]. Furthermore, in perimenopausal women, anthropometric and lifestyle risk factors have been shown to explain only 19 to $25 \%$ of the variability of BMD at the central skeletal measurement sites [13]. These findings are consistent with what we found among our postmenopausal women at a mean age of 61 years: the combination of age and anthropometric parameters (height, weight) and risk factors discriminated less powerfully between women with and without osteoporosis than equations that included RA measurement - even taken alone - as shown by the significantly larger AUC achieved when incorporating RA.

There is no evidence in the literature to date that antiosteoporotic treatment reduces fracture risk in patients treated solely on the basis of risk factors. In fact, the opposite has been suggested by a recent hip fracture endpoint study in which risedronate failed to show any significant effect in elderly women selected on the basis of their risk profile for hip fracture, while hip fracture incidence was significantly reduced in women included on the basis of a low BMD value at their femoral neck [31]. Therefore, the presence of risk factors alone has to

Table 3 Areas under the ROC curves by DXA reimbursement groups

\begin{tabular}{|c|c|c|c|c|c|c|}
\hline & \multicolumn{3}{|c|}{$\begin{array}{l}\text { Women with reimbursed DXA indication } \\
\text { (group 1) }\end{array}$} & \multicolumn{3}{|c|}{$\begin{array}{l}\text { Women without reimbursed DXA } \\
\text { indication (group 2) }\end{array}$} \\
\hline & $\begin{array}{l}\text { Area under } \\
\text { the ROC curve }\end{array}$ & $95 \% \mathrm{CI}$ & $P$ value & $\begin{array}{l}\text { Area under } \\
\text { the ROC curve }\end{array}$ & $95 \% \mathrm{CI}$ & $P$ value \\
\hline Model 1: age, height, weight & 0.709 & $0.632-0.786$ & & 0.702 & $0.62-0.79$ & \\
\hline $\begin{array}{l}\text { Model 2: age, height, } \\
\text { weight }+ \text { risk factors* }\end{array}$ & 0.715 & $0.639-0.790$ & $P=0.72^{\mathrm{a}}$ & 0.707 & $0.62-0.80$ & $P=0.63^{\mathrm{a}}$ \\
\hline Model 3: RA alone & 0.781 & $0.717-0.845$ & $P=0.12^{\mathrm{a}}$ & 0.805 & $0.72-0.89$ & $P=0.04^{\mathrm{a}}$ \\
\hline $\begin{array}{l}\text { Model 4: RA + age, height, } \\
\text { weight }\end{array}$ & 0.823 & $0.764-0.881$ & $\begin{array}{l}P=0.0008^{\mathrm{a}} \\
P=0.04^{\mathrm{b}}\end{array}$ & 0.824 & $0.75-0.90$ & $\begin{array}{l}P=0.004^{\mathrm{a}} \\
P=0.25^{\mathrm{b}}\end{array}$ \\
\hline $\begin{array}{l}\text { Model 5: RA + age, height, } \\
\text { weight }+ \text { risk factors* }\end{array}$ & 0.830 & $0.773-0.887$ & $\begin{array}{l}P=0.0004^{\mathrm{a}} \\
P=0.02^{\mathrm{b}}\end{array}$ & 0.842 & $0.77-0.91$ & $\begin{array}{l}P=0.001^{\mathrm{a}} \\
P=0.08^{\mathrm{b}}\end{array}$ \\
\hline
\end{tabular}

${ }^{a}$ Significance level when compared to model 1 ; ${ }^{b}$ significance level when compared to model 3. * Risk factors: fracture following a low velocity trauma, clinically evident osteoporosis (including height loss), history of hypogonadism, gastrointestinal disease, long-term treatment with glucocorticosteroids, primary hyperparathyroidism, history of hysterectomy or ovariectomy, low dietary calcium intake, positive family history of osteoporosis, nicotine abuse ( $>10$ cigarettes/day), substitution with thyroidal hormones 
Table 4 RA cut-off values with related sensitivity and specificity for women without reimbursed DXA indication (group 2)

\begin{tabular}{|c|c|c|c|c|c|c|}
\hline \multicolumn{2}{|c|}{$\begin{array}{l}\text { RA cut-off } \\
\text { (arbitrary units, AU) }\end{array}$} & \multirow{2}{*}{$\begin{array}{l}\text { Osteoporosis }{ }^{\mathrm{a}}, \\
n=35 \\
33\end{array}$} & \multirow{3}{*}{$\begin{array}{l}\text { No osteoporosis }{ }^{\mathrm{b}}, \\
n=157 \\
107 \\
50\end{array}$} & \multirow{3}{*}{$\begin{array}{l}\begin{array}{l}\text { Positive tests } \\
(\%, 95 \% \mathrm{CI})\end{array} \\
72.9 \\
(66.0-79.1)\end{array}$} & \multirow{3}{*}{$\begin{array}{l}\begin{array}{l}\text { Sensitivity } \\
(\%, 95 \% \mathrm{CI})\end{array} \\
\begin{array}{l}94.3 \\
(80.8-99.3)\end{array}\end{array}$} & \multirow{3}{*}{$\begin{array}{l}\begin{array}{l}\text { Specificity } \\
(\%, 95 \% \mathrm{CI})\end{array} \\
\begin{array}{l}31.8 \\
(24.6-39.7)\end{array}\end{array}$} \\
\hline$<100 \mathrm{AU}$ & Yes & & & & & \\
\hline & No & 2 & & & & \\
\hline \multirow[t]{2}{*}{$<95 \mathrm{AU}$} & Yes & 32 & 85 & 60.9 & 91.4 & 45.9 \\
\hline & No & 3 & 72 & $(53.7-67.9)$ & $(76.9-98.2)$ & $(37.9-54.0)$ \\
\hline \multirow[t]{2}{*}{$<90 \mathrm{AU}$} & Yes & 30 & 65 & 49.5 & 85.7 & 54.6 \\
\hline & No & 5 & 92 & $(42.2-56.8)$ & $(69.7-95.2)$ & $(50.5-66.4)$ \\
\hline \multirow[t]{2}{*}{$<87.5 \mathrm{AU}$} & Yes & 28 & 51 & 41.1 & 80.0 & 67.5 \\
\hline & No & 7 & 106 & $(34.1-48.5)$ & $(63.0-91.6)$ & $(59.6-74.8)$ \\
\hline \multirow[t]{2}{*}{$<85 \mathrm{AU}$} & Yes & 23 & 43 & 34.4 & 65.7 & 72.6 \\
\hline & No & 12 & 114 & $(27.7-41.6)$ & $(47.8-80.9)$ & $(64.9-79.4)$ \\
\hline
\end{tabular}

${ }^{\mathrm{a}} \mathrm{T}$-score $\leq-2.5 \mathrm{SD}$ at spine and/or hip, ${ }^{\mathrm{b}} \mathrm{T}$-score $>-2.5 \mathrm{SD}$ at spine and hip

Table 5 Sensitivity and specificity of current DXA reimbursement criteria in Switzerland (all women, with or without reimbursed DXA indication)

\begin{tabular}{|c|c|c|c|c|c|c|}
\hline Test & & $\begin{array}{l}\text { Osteoporosis }{ }^{\mathrm{a}}, \\
n=109\end{array}$ & $\begin{array}{l}\text { No osteoporosis }{ }^{\mathrm{b}} \\
n=273\end{array}$ & $\begin{array}{l}\text { Positive tests } \\
(\%, 95 \% \mathrm{CI})\end{array}$ & $\begin{array}{l}\text { Sensitivity } \\
(\%, 95 \% \mathrm{CI})\end{array}$ & $\begin{array}{l}\text { Specificity } \\
(\%, 95 \% \mathrm{CI})\end{array}$ \\
\hline Presence of reimbursed DXA indication & $\begin{array}{l}\text { Yes } \\
\text { No }\end{array}$ & $\begin{array}{l}74 \\
35\end{array}$ & $\begin{array}{l}116 \\
157\end{array}$ & $\begin{array}{l}48.5 \\
(43.4-53.5)\end{array}$ & $\begin{array}{l}67.9 \\
(58.2-76.3)\end{array}$ & $\begin{array}{l}57.5 \\
(51.4-63.4)\end{array}$ \\
\hline
\end{tabular}

${ }^{\mathrm{a}} \mathrm{T}$-score $\leq-2.5 \mathrm{SD}$ at spine and/or hip, ${ }^{\mathrm{b}} \mathrm{T}$-score $>-2.5 \mathrm{SD}$ at spine and hip

Table 6 Sensitivity and specificity of the RA cut-off value 95 AU for the pooled patient population (all women, with or without reimbursed DXA indication)

\begin{tabular}{|c|c|c|c|c|c|c|}
\hline \multicolumn{2}{|c|}{$\begin{array}{l}\text { RA cut-off } \\
\text { (arbitrary units, AU) }\end{array}$} & \multirow{2}{*}{$\begin{array}{l}\text { Osteoporosis }{ }^{\mathrm{a}}, \\
n=109 \\
104 \\
5\end{array}$} & \multirow{2}{*}{$\begin{array}{l}\text { No osteoporosis }{ }^{\mathrm{b}}, \\
n=273 \\
158 \\
115\end{array}$} & \multirow{2}{*}{$\begin{array}{l}\begin{array}{l}\text { Positive tests } \\
(\%, 95 \% \mathrm{CI})\end{array} \\
66.9 \\
(61.9-71.5)\end{array}$} & \multirow{2}{*}{$\begin{array}{l}\text { Sensitivity } \\
(\%, 95 \% \text { CI })\end{array}$} & \multirow{2}{*}{$\begin{array}{l}\begin{array}{l}\text { Specificity } \\
(\%, 95 \% \mathrm{CI})\end{array} \\
\begin{array}{l}42.2 \\
(36.2-48.2)\end{array}\end{array}$} \\
\hline$<95 \mathrm{AU}$ & $\begin{array}{l}\text { Yes } \\
\text { No }\end{array}$ & & & & & \\
\hline
\end{tabular}

${ }^{\mathrm{a}} \mathrm{T}$-score $\leq-2.5 \mathrm{SD}$ at spine and/or hip, ${ }^{\mathrm{b}} \mathrm{T}$-score $>-2.5 \mathrm{SD}$ at spine and hip

be considered as insufficient to start osteoporosis therapy. Furthermore, although the BMD of any skeletal site may be useful in estimating an individual's overall risk of fracture [32], BMD at the lumbar spine and/or hip remains the key to decision making for treatment initiation against osteoporosis, as documented by the inclusion criteria in virtually all major recent fracture endpoint studies with risedronate [31,33,34], alendronate [35, 36, 37, 38], calcitonin [39], raloxifene [40, 41] and teriparatide $[42,43]$.

As proposed in the present study, risk questionnaires and peripheral BMD measurement devices may not only be used to estimate a person's fracture risk, but may also serve as case-finding tools to preselect those patients most likely to have low BMD at the key sites of the spine and hip, in whom the decision whether to treat or not can be made after the diagnosis of osteoporosis has been established or ruled out by subsequent hip and/or spine DXA measurement.

For the present study, we chose RA as part of the case-finding strategy for osteoporotic patients for three main reasons. First, the phalangeal measurement site is easily accessible and there is widespread access to conventional X-ray devices among Swiss practicing physicians. Second, RA has been shown previously to predict low bone mass at the spine and the hip [21,25] and to be predictive for vertebral deformities [22], non-vertebral, vertebral and overall fracture risk [23] as well as hip fracture risk [24]. Third, our prior experience with RA showed that the use of phalangeal X-ray as a first-line risk stratification tool followed by DXA only in those patients with a measured RA value below a selected threshold could potentially be cost efficient when compared to an approach using DXA in all postmenopausal women, i.e., not limited to those women with risk factors for osteoporosis [25].

In the present study, the participating physicians selected women with one or several risk factors for osteoporosis, i.e., women in whom they had a clinical suspicion of osteoporosis. The large majority of women with a reimbursed DXA indication (group 1) had anamnestic fractures and/or documented height loss. In these women, age, weight and RA were significant predictors of low BMD at the spine and/or hip. An 
unexpected finding was that women on long-term treatment with glucocorticosteroids had normal BMD more frequently than osteoporosis. One possible explanation could be the high awareness and anxiety related to the iatrogenic side effects of glucocorticosteroids on bone, leading the participating physicians to include women with low dose or inhaled glucocorticosteroids in the study. In the group of women without reimbursed DXA indications (group 2), age, height, weight and RA were significant predictors of low BMD at the spine and/ or the hip. In this group, RA led to a significantly larger AUC than age, height and weight combined, while the addition of other risk factors to the logistic regression model did not improve the AUC further. The sensitivity and specificity results in group 2 were less favorable to RA than the results published earlier in a representative sample of postmenopausal women [25], where at a sensitivity level of $90 \%$ the specificity of RA to detect osteoporosis was $67 \%$. This result was expected, as those women with the highest fracture risk (i.e., those with previous fracture and/or height loss) were per definition excluded from group 2.

Concerning the sensitivity and specificity of the currently accepted criteria for DXA reimbursement, the present study clearly demonstrates that adherence to these criteria leads to significant under-diagnosing of the disease. Restricting DXA reimbursement and thereby DXA measurements at the spine and the hip to women who fulfill one of these criteria leads to the correct identification of only $68 \%(74 / 109)$ of the total of osteoporotic patients in this population, while $32 \%(35 / 109)$ remain unidentified and therefore untreated - in the worst case until a first fracture occurs (Table 5). In the patient population participating in this study (patients with generally accepted risk factors for osteoporosis) and if following the DXA reimbursement rules, the practicing physicians would only have addressed $50 \%$ of their postmenopausal women at risk for DXA measurement and thereby would have missed $30 \%$ of the cases with underlying of osteoporosis.

Alternatively, measuring phalangeal RA systematically in all postmenopausal women with clinical suspicion of osteoporosis, whether or not they match with the DXA reimbursement criteria, a cut-off value can be set at a chosen level that meets the sensitivity expectations of a medical screening test. For example, choosing a cutoff value of $95 \mathrm{AU}$ as an indication for a DXA would allow to correctly identify $95 \%$ (104/109) of all women with osteoporosis at the spine and/or the hip, while avoiding DXA measurements in $33 \%$ of all women (Table 6). On the other hand, choosing a sensitivity similar to that achieved by the current reimbursement criteria, i.e., around $65 \%, 56 \%$ of women would not undergo subsequent DXA measurement. Theoretically and using this approach, a cost neutral price of RA could be calculated as a percentage of the cost of DXA, at which the proposed two-step case-finding approach would be cost-effective, while identifying more patients with osteoporosis. A more practical approach would be to simply add one new criterion for DXA reimbursement, i.e., a phalangeal RA value below a certain cut-off in women who do not otherwise qualify for reimbursed DXA, in line with the women in group 2 of the present study. Assuming, e.g., a cut-off value of $95 \mathrm{AU}$ in that group, this strategy would have a sensitivity of $91.4 \%$, an acceptable specificity of $45.9 \%$ and only three women with osteoporosis would be missed (Table 4). This strategy would increase the percentage of (correctly) identified patients with osteoporosis from $68 \%(74 / 109)$ to $97 \%(106 / 109)$ compared with the current strategy proposed by the health care authorities (i.e., to measure only women with reimbursement criteria). Compared with a broad screening usage of DXA (meaning that all women in group 2 would have DXA measurements, too), this strategy would avoid DXA measurements in $39.1 \%$ of the women from that group. In earlier studies, the pre-identification of patients with low bone mass with ultrasound or peripheral DXA bone measurements has been shown to have good sensitivity and specificity in patients with a mean age of 60 to 65 years $[18,19,44$, $45,46]$. In contrast, the same methods applied to perimenopausal women aged 45 to 55 years showed poor specificity if sensitivity was preserved [47]. In the present study, the women in group 1 (mean age of 70.2 years and $39 \%$ of the women with osteoporosis) were younger than the women in group 2 (mean age 64.9 years and $18 \%$ of the women with osteoporosis). Whether the results observed for these patients with risk factors in these age groups can be generalized to younger patients, i.e., to perimenopausal women, could not be answered by this study.

Apart from their general significance for the elaboration of optimum case-finding strategies for osteoporosis, these results are of special interest for patients not living near an osteoporosis center, since the above figures (33 and 39.1\%, respectively) of DXA measurements avoided represent the percentages of women for whom a visit to the osteoporosis center can be avoided without compromising on diagnostic quality, as RA can be done in the nearby physician's practice.

\section{Conclusion}

In conclusion, if the results observed in the present study could be generalized to women for whom primary care physicians are considering the possibility of underlying osteoporosis, RA would be a valid preselection tool for women with risk factors but who do not meet the current eligibility criteria for DXA reimbursement in Switzerland. We therefore propose that detrimental RA values should be added to the list of reimbursed conditions for DXA measurement. Patients with clinically evident osteoporosis, fractures following a low velocity trauma, long-term treatment with glucocorticosteroids, hypogonadism, gastrointestinal diseases (malabsorption, Crohn's disease and hemorrhagic colitis) or primary hyperparathyroidism should continue to directly undergo a DXA measurement 
to avoid incremental costs. To validate the best RA cut-off value to choose, further investigations using a prospective study design are necessary.

Acknowledgments We thank Merck Sharp \& Dohme-Chibret AG Switzerland for providing the digital processing system. We are grateful to all participating physicians who recruited the patients and trusted in the competence of our center, to Professor Philippe Jaeger for initiating the collaboration with Dr. Abetel and the Swiss College of Family practitioners, and to Dr. Philippe Kress for his invaluable contribution to the preparation of the manuscript.

\section{Appendix}

The 90 participating physicians recruiting 423 patients were: Abetel Gilbert, Orbe; Adank Christian, Lyssach; Aeschlimann Kurt, Langenthal; Affolter Ulrich, Weier i. E.; Bachmann Martin, Hindelbank; Bandi Benvenuto, Burgdorf; Bentz Laurent, Jegenstorf; Bettler Markus, Ins; Bettschen Hans Ulrich, Spiez; Bettschen Liana, Spiez; Boss Dieter Urs, Gwatt; Brügger Daniel, Laupen; Brunner Hansuli, Thun; Buchli Axel; Neuenegg; Buchli Richard, Ueberstorf; Bugnon Gérard, Liebefeld; Bugnon-Hartmann Roswitha, Bern; Burach Haefliger Helen, Nidau; Castelberg Ulrich, Aarbeg; de Vevey Pierre, Chavornay; de Vevey Maryse, Chavornay; Dettwiler Hansueli, Biel/Bienne; Egloff Stefan, Biel/Bienne; Fahrni Urs Walter, Thun; Flückiger Alex, Biel; Galland Christiane, Romainmôtier; Gehri Paul, Biel / Bienne; Glardon Michel, Tavannes; Golder Simon, Thun; Grossen Rudolf, Aeschi; Haase Serge, Thun; Hagnauer Ulrich, Thun; Hungerbuhler Philippe, Yverdon; Kammer Peter, Münsingen; Karly Michel, Orbe; Kieliger Franz, Grenchen; Kinsbergen Manus, Biel/Bienne; Kneubühler Hans-Rudolf, Steffisburg; Kohler Samuel, Münchenbuchsee; Koller-Stebler Franz, Biel; Kölliker Franz, Biel; Kreutz Helène, Thun; Lanz Markus, Wattenwil; Lasserre Bernard, Orbe; Lasserre Murielle, Orbe; Leuenberger Jean-Frédéric, Bonvillars; Luder Paul, Steffisburg; Mancini Maxime, Orbe; Marth Jürg, Biel/ Bienne; Meinerzhagen Andreas, Wabern; Merz Philippe, Biel; Messerli Hans-Rudolf, Burgdorf; Michel Ernst, Bern; Mösli P.R.,Rüfenacht, Moser Ruedi, Bern; Moser Samuel, Frutigen; Müller Norbert, Frutigen; Müry Hans Rudolf, Bern; Neuenschwander Christoph, Liebefeld; Oberson Bernhard, Belp; Raaflaub Walter, Schönried; Rohrer Jörg, Bern; Rordorf Richard, Thun; Rösler Daniela, Bern; Rutishauser Andreas, Bern; Sanacare HMO Gesundheitszentrum, Bern; Schacke Stefan, Steffisburg; Schärer Hans, Aarberg; Schafroth Ulrich, Münsingen; Schmid Peter, Konolfingen; Schönenberger Peter, Belp; Schweizer Thomas, Liebefeld; Sieber Johannes, Meikirch; Siegenthaler Henri, Biel/Bienne; Stahel Peter, Sumiswald; Stöcklin Emanuel, Lengnau; Tapis Matthias, Uetendorf; Thommen Susanne, Gwatt; Tièche Marcel, Grenchen; Toth Thomas, Thun; Trachsel Christoph, Reichenbach; von Tscharner Françoise, Zimmerwald; Weiss Severin, Bern; Wildbolz
Mathias, Wynigen; Witz Marc, Münchenbuchsee; Wyss Erwin, Biel/Bienne; Zulliger Urs, Hinterkappelen; Zumofen Walter A., Frutigen; Zwicky Nikolaus, Thun.

\section{References}

1. Melton L, Atkinson E, O'Fallon W, Wahner H, Riggs B (1993) Long-term fracture prediction by bone mineral assessed at different skeletal sites. J Bone Miner Res 8:1227-1233

2. Cummings S, Black D, Nevitt M, et al (1993) Bone density at various sites for prediction of hip fractures: The study of osteoporotic fractures. Lancet 341:72-75

3. WHO Study Group (1994) Assessment of fracture risk and its application to screening for postmenopausal osteoporosis. Report of a WHO Study Group, no. 843. WHO, Geneva

4. Marshall D, Johnell O, Wedel H (1996) Meta-analysis of how well measures of bone mineral density predict occurrence of osteoporotic fractures. BMJ 312:1254-1259

5. Lydick E, Cook K, Turpin J, Melton M, Stine R, Byrnes C (1998) Development and validation of a simple questionnaire to facilitate identification of women likely to have low bone density. Am J Manag Care 4:37-48

6. Bauer DC, Browner WS, Cauley JA et al (1993) Factors associated with appendicular bone mass in older women. The Study of Osteoporotic Fractures Research Group. Ann Intern Med 118:657-665

7. Thompson PW (2000) A fracture risk profile using single-site bone density assessment and clinical risk factors. J Clin Densitom 3:73-77

8. Ungar WJ, Josse R, Lee S et al (2000) The Canadian SCORE questionnaire: optimizing the use of technology for low bone density assessment. Simple Calculated Osteoporosis Risk Estimate. J Clin Densitom 3:269-280

9. O'Neill TW, Cooper C, Cannata JB et al (1994) Reproducibility of a questionnaire on risk factors for osteoporosis in a multicentre prevalence survey: the European Vertebral Osteoporosis Study. Int J Epidemiol 23:559-565

10. Ribot C, Pouilles JM, Bonneu M, Tremollieres F (1992) Assessment of the risk of post-menopausal osteoporosis using clinical factors. Clin Endocrinol (Oxf) 36:225-228

11. Compston JE (1992) Risk factors for osteoporosis. Clin Endocrinol (Oxf) 36:223-224

12. Johnell O (1996) Advances in osteoporosis: better identification of risk factors can reduce morbidity and mortality. J Intern Med 239:299-304

13. Kroger H, Tuppurainen M, Honkanen R, Alhava E, Saarikoski S (1994) Bone mineral density and risk factors for osteoporosis - a population-based study of 1,600 perimenopausal women. Calcif Tissue Int 55:1-7

14. Cadarette SM, Jaglal SB, Kreiger N, McIsaac WJ, Darlington GA, Tu JV (2000) Development and validation of the Osteoporosis Risk Assessment Instrument to facilitate selection of women for bone densitometry. CMAJ 162:1289-1294

15. Geusens P, Hochberg MC, van der Voort DJ et al (2002) Performance of risk indices for identifying low bone density in postmenopausal women. Mayo Clin Proc 77:629-637

16. Kanis JA (2002) Diagnosis of osteoporosis and assessment of fracture risk. Lancet 359:1929-1936

17. Meunier PJ, Delmas PD, Eastell R (1999) Diagnosis and management of osteoporosis in postmenopausal women: clinical guidelines. International Committee for Osteoporosis Clinical Guidelines. Clin Ther 21:1025-1044

18. Benitez CL, Schneider DL, Barrett-Connor E, Sartoris DJ (2000) Hand ultrasound for osteoporosis screening in postmenopausal women. Osteoporos Int 11:203-210

19. Fiter J, Nolla JM, Gomez-Vaquero C, Martinez-Aguila D, Valverde J, Roig-Escofet D (2001) A comparative study of computed digital absorptiometry and conventional dual-energy $\mathrm{X}$-ray absorptiometry in postmenopausal women. Osteoporos Int 12:565-569 
20. Bouxsein ML, Michaeli DA, Plass DB, Schick DA, Melton ME (1997) Precision and accuracy of computed digital absorptiometry for assessment of bone density of the hand. Osteoporos Int 7:444-449

21. Cosman F, Herrington B, Himmelstein S, Lindsay R (1991) Radiographic absorptiometry: a simple method for determination of bone mass. Osteoporos Int 2:34-38

22. Versluis RG, Petri H, Vismans FJ, van de Ven CM, Springer MP, Papapoulos SE (2000) The relationship between phalangeal bone density and vertebral deformities. Calcif Tissue Int $66: 1-4$

23. Huang C, Ross PD, Yates AJ et al (1998) Prediction of fracture risk by radiographic absorptiometry and quantitative ultrasound: a prospective study. Calcif Tissue Int 63:380-384

24. Mussolino ME, Looker AC, Madans JH et al (1997) Phalangeal bone density and hip fracture risk. Arch Intern Med 157:433-438

25. Lippuner K, Fuchs G, Ruetsche AG, Perrelet R, Casez JP, Neto I (2000) How well do radiographic absorptiometry and quantitative ultrasound predict osteoporosis at spine or hip? A cost-effectiveness analysis. J Clin Densitom 3:241-249

26. Yang S, Hagiwara S, Engelke K, et al (1994) Radiographic absorptiometry for bone mineral measurement of the phalanges: precision and accuracy study. Radiology 192:857-859

27. Kleerekoper M, Nelson D, Flynn M, Pawluszka A, Jacobsen G, Peterson E (1994) Comparison of radiographic absorptiometry with dual-energy X-ray absorptiometry and quantitative computed tomography in normal older white and black women. J Bone Miner Res 9:1745-1749

28. Yates A, Ross P, Lydick E, Epstein R (1995) Radiographic absorptiometry in the diagnosis of osteoporosis. Am J Med 98 [Ssuppl 2]:2A-41S.

29. Tothill P (1998) Methods of bone mineral measurement. Phys Med Biol 31:546-550

30. Kalender W (1992) Effective dose values in bone mineral measurements by photon absorptiometry and computed tomography. Osteoporos Int 2:82-87

31. McClung MR, Geusens P, Miller PD et al (2001) Effect of risedronate on the risk of hip fracture in elderly women. Hip Intervention Program Study Group. N Engl J Med. 344:333340

32. Consensus Development Conference (1993) Diagnosis, prophylaxis and treatment of osteopororosis. Am J Med 94:646650

33. Fogelman I, Ribot C, Smith R, Ethgen D et al (2000) Risedronate reverses bone loss in postmenopausal women with low bone mass: results from a multinational, double-blind, placebocontrolled trial. J Clin Endocrinol Metab 85:1895-900

34. Harris ST, Watts NB, Genant HK, McKeever CD et al (1999) Effects of risedronate treatment on vertebral and nonvertebral fractures in women with postmenopausal osteoporosis: a randomized controlled trial. JAMA 282:1344-1352
35. Liberman UA Weiss SR, Bröll J, Minne HW et al (1995) Effect of oral alendronate on bone mineral density and the incidence of fractures in postmenopausal osteoporosis. N Engl J Med 333:1437-1443

36. Black DM, Cummings SR, Karpf DB, Cauley JA et al (1996) Randomised trial of effect of alendronate on risk of fracture in women with existing vertebral fractures. Lancet 348:1535-1541

37. Cummings SR, Black DM, Thompson DE, Applegate WB et al (1998) Effect of alendronate on risk of fracture in women with low bone density but without verlebral fractures: results from the Fracture Intervention Trial. JAMA 280:2077-2082

38. Black DM, Thompson D, Bauer DC, Ensrud K et al (2000) Fracture risk reduction with alendronate in women with osteoporosis: the Fracture Intervention Trial. J Clin Endocrinol Metab 85:4118-4124

39. Chesnut CH, Silverman S, Andriano K, Genant H et al (2000) A randomized trial of nasal spray salmon calcitonin in postmenopausal women with established osteoporosis: the prevent recurrence of osteoporotic fractures study. Am J Med 109:267-276

40. Delmas PD, Ensrud KE, Adachi JD, Harper KD et al (2002) Efficacy of raloxifene on vertebral fracture risk reduction in postmenopausal women with osteoporosis: 4-year results from a randomized clinical trial. J Clin Endocrinol Metab 87:36093617

41. Ettinger B, Black DM, Mitlak BH, Knickerbocker RK et al (1999) Reduction of vertebral fracture risk in postmenopausal women with osteoporosis treated with raloxifene: results from a 3-year randomized clinical trial. JAMA 282:637-645

42. Neer RM, Arnaud CD, Zanchetta JR, Prince R et al (2001) Effect of parathyroid hormone (1-34) on fractures and bone mineral density in postmenopausal women with osteoporosis. N Engl J Med 344:1434-1441

43. Lindsay R, Nieves J, Formica C, Henneman E et al (1997) Randomised controlled study of effect of parathyroid hormone on vertebral-bone mass and fracture incidence among postmenopausal women on oestrogen with osteoporosis. Lancet 350:550-555

44. Hodson J, Marsh J (2003) Quantitative ultrasound and risk factor enquiry as predictors of postmenopausal osteoporosis: comparative study in primary care. BMJ 326:1250-1251

45. Diez-Perez A, Marin F, Vila J, Abizanda M et al (2003) Evaluation of calcaneal quantitative ultrasound in a primary care setting as a screening tool for osteoporosis in postmenopausal women. J Clin Densitom 6:237-245

46. Hernandez JL, Marin F, Gonzalez-Macias J, Diez-Perez A et al (2004) Discriminative capacity of calcaneal quantitative ultrasound and of osteoporosis and fracture risk factors in postmenopausal women with osteoporotic fractures. Calcif Tissue Int 74:357-365

47. Martin JC, Reid DM (1996) Appendicular measurements in screening women for low axial bone mineral density. $\mathrm{Br}$ J Radiol 69:234-240 